\title{
Barriers to Integrate Physical Exercise Into the Ethiopian Healthcare System to Treat Non-Communicable Diseases
}

\author{
Melkamu D. Kassa ${ }^{1} \&$ Jeanne Grace ${ }^{1}$ \\ ${ }^{1}$ University of KwaZulu-Natal, Discipline of Biokinetics, Exercise \& Leisure Sciences, Durban, South Africa \\ Correspondence: Melkamu Dugassa (PhD), University of KwaZulu-Natal, Discipline of Biokinetics, Exercise \& \\ Leisure Sciences, Durban, Westville, 3630, South Africa. Tel: 31-260-7985, Fax: 31-260-7985. E-mail: \\ kassamd2015@gmail.com
}

Received: July 8, 2018 Accepted: July 24, 2018 Online Published: September 19, 2018

doi:10.5539/gjhs.v10n10p123 URL: https://doi.org/10.5539/gjhs.v10n10p123

\begin{abstract}
Introduction: Physical exercise is recognized as one component of non-communicable disease prevention, but little attention has been devoted to integrating physical exercise into the Ethiopian healthcare system, with the barriers to its inclusion being unclear.

Objectives: The present study explores the bottlenecks to integrate physical exercise into the Ethiopian healthcare system to treat non-communicable disease.

Design: A mixed method sequential explanatory design.

Setting: Public referral hospitals in Ethiopia.

Methodology: Data was collected in two phases among 312 (195 males and 117 females) healthcare professionals. The participants were selected proportionately and randomly from 13 public referral hospitals.

Results: Lack of: national coordination to promote physical exercise $(\mathrm{t}(311)=69.20, \mathrm{p}<.0005)$, trained physical exercise professionals $(\mathrm{t}(311)=14.42, \mathrm{p}<.0005)$; physical exercise guidelines $(\mathrm{t}(311)=33.25, \mathrm{p}<.0005)$; training how to prescribe physical exercise by healthcare providers $(\mathrm{t}(311)=62.94, \mathrm{p}<.0005)$; information on the health benefits of physical exercise to give to their patients $(\mathrm{t}(311)=65.62, \mathrm{p}<.0005)$; and built environment that encourages physical exercise participation $(\mathrm{t}(311)=59.64, \mathrm{p}<.0005)$ were identified as barriers. Additionally, built environment, policy, healthcare professionals' lifestyle, demography of healthcare professionals, health information coverage of physical exercise and the hospital physical building were also identified as barriers.

Conclusions: Physical exercise appears marginalized from the Ethiopian healthcare system. Healthcare organizations and policy makers could take the cited barriers into consideration to plan, design and integrate physical exercise into the healthcare system to prevent NCDs in Ethiopia.
\end{abstract}

Keywords: exercise, health policy, healthcare professionals, hospital, built environment

\section{Introduction}

Non-communicable diseases (NCDs), particularly cardiovascular, diabetes, cancer, hypertension and respiratory diseases are the main causes of morbidity and mortality globally (Mensah, 2016; Fatt, 2016). Compelling evidence has shown an increase in the burden of NCDs, creating the need for a worldwide response to decreasing the associated morbidity and mortality (Pearce et al., 2013; Varghese, 2013). NCDs are one of the main health and developmental challenges of the 21 st century in relation to the social and economic consequences they cause in all countries and are particularly overwhelming in poor and vulnerable populations. According to the World Health Organization (WHO) global status report, NCDs are accountable for 38 million (68\%) of the global 56 million deaths in 2012; more than 16 million (40\%) were amongst early, affecting people under the age of 70 (WHO, 2014). Nearly three-quarters of all NCDs mortalities, and the majority of premature deaths, namely 28 million (82\%), occur in low- and middle-income countries. Premature deaths from NCDs range from $22 \%$ among men and $35 \%$ amongst women in low-income countries, to $8 \%$ amongst men and $10 \%$ amongst women in high-income countries (WHO, 2014; WHO, 2015).

As with other low-income countries, the burden of NCDs is currently growing in Ethiopia. According to World Health Organization NCDs progress monitor, 30\% of total annual deaths in Ethiopia can be attributed to NCDs, 
particularly due to cardiovascular disease, diabetes, and hypertension, with $15 \%$ of those occurring prematurely (WHO, 2015). It is documented that the major NCDs share common risk factors, such as tobacco use, alcohol drinking, unhealthy diet and lack of physical exercise, and that their risk factors are associated with lifestyle changes, urbanization, globalization, and industrialization (Engelen, Lina, Adrian et al., 2017). In Ethiopia, the rate of urbanization is increasing at $4.89 \%$ per annum, resulting in lifestyle changes for many people (Kay \& Nagesha, 2016). Studies show that NCDs risk factors are more prevalent in urban settings due to the availability of alcohol, tobacco, junk energy food and a more sedentary lifestyle (Bishwajit, Ide, Hossain, \& Safa, 2014 ; Eckert, Sophie, 2014). The strategy to address NCDs in Ethiopia is mainly focused on prescribing drugs to treat the resulting conditions, rather than have effective prevention strategies. Compelling pieces of evidence indicate that treating major NCDs, such as coronary heart disease, type 2 diabetes, and hypertension, causes an increase in medical expenses for the consumer and the healthcare providers, specifically the public health sector (Krueger, Turner, Krueger, \& Ready, 2014; Shuval, Leonard, Drope et al., 2017).

Similarly, studies have revealed that the lack of physical exercise is a growing public health issue, contributing to diverse health problems (Kohl, Harold, Cora et al., 2012; Shuval et al., 2017). In this regard, Fatt (2016) highlighted that a lack of regular physical exercise is one of the modifiable risk factors of NCDs, and has been identified as the fourth leading risk factor for such conditions (Lee et al., 2012) after high blood pressure (13\%), tobacco use (9\%) and high blood glucose (6\%) (Varghese, 2013; WHO, 2014).

According to the description of Hoeger and Hoeger, (2015), physical exercise is "any type of physical activity that is planned, structured, and requires repetitive bodily movement designed to improve and maintain the health and wellness of individuals." Studies demonstrated that 150 minutes of moderate intensity, or 75 minutes of vigorous intensity physical exercise for three to five days per week, incorporating aerobic and strengthening exercises, improves health (Taylor, 2014: Allis, 2017). Currently, many countries have established and integrated the Exercise is Medicine (EIM) program into their healthcare system to treat NCDs, this initiative having been established in 2008 by the American College of Sports Medicine (Duperly et al., 2014; Lobelo, Stoutenberg, \& Hutber, 2014).

A growing body of studies acknowledge the benefits of physical exercise as part of the human life, health, and wellbeing (Nunan, Mahtani, Roberts, \& Heneghan, 2013). As early as 400 B.C., Hippocrates noted the subsequent interpretations: "all parts of the body which have a function, if used in moderation and exercised in toils in which each is accustomed, become thereby healthy, well-developed and age more slowly. However, if unused and left to idle they become liable to disease, defective in growth, and age more quickly" (Rikli, 2005). As evidenced by this quote, the benefits of physical exercise have long been recognized as a means of preserving and enhancing health. Recently, Kokkinos quoted the notion of ancient Greek thinker Hippocrates; "Walking is a man's best medicine" (Kokkinos, 2012). Studies show that if used properly, physical exercise acts as a medicine to prevent and manage a group of NCDs and their complications, such as diabetes, hypertension, obesity, cardiovascular disease, depression, asthma, cancer, falls and fractures, as well as to improve wellbeing and positively affect individuals (Archer \& Blair, 2012; Nunan et al., 2013; Greenwood et al., 2016; Speake, Helen, Robert et al., 2016). Similarly, epidemiological evidence from systematic reviews indicates a converse, autonomous and graded association between the amount of physical exercise, health and general mortality (Lee et al., 2012; Taylor, 2014). As shown by Lee et al., (2012), a lack of physical exercise accounts for $6 \%$ of cardiovascular disease, $7 \%$ of diabetes, $9 \%$ of early deaths, and $6 \%$ of global mortality of 60 million deaths in 2012 .

Despite the numerous health benefits of physical exercise, and it is one of the essential approaches to maintaining good public health, more than $60 \%$ of the global population do not reach the recommended level of activity (Hallal et al., 2012; WHO, 2017). There is growing evidence of a decline in physical exercises globally associated with urbanization, technological advancement, more sedentary lifestyles, desk-based jobs and time pressure that reduces the activity of human beings (Ng \& Popkin, 2012; Hinckson, Erica, Scott et al., 2014). Globally, efforts have been made to make physical exercise an integral part of the healthcare system, which remains challenging, particularly in low-resource countries (Reis et al., 2016; Brien, Shields, Oh, \& Fowles, 2017). Studies show that most healthcare providers do not communicate and recommend physical exercise to their patients as part of healthcare (Thornton, Jane, Pierre et al., 2016; Brien et al., 2017). However, the barriers preventing them to integrate physical exercise in the healthcare system to prevent NCDs is less acknowledged.

A cross-sectional study on international physical therapists showed that patients lack motivation and priority to undertake the physical activity given to them by healthcare professionals were barriers to integrating physical exercise in the healthcare system (Soundy, Stubbs, Probst et al., 2014; Firth, Rosenbaum, Stubbs et al., 2016). A systematic review conducted on six qualitative articles stated that environmental factors (access, transport, and 
cost), health problems, unfavourable activities, confusion, and fear of failure were barriers to physical exercise (Brookfield \& Mead, 2016). Other studies indicate strong and positive associations between the built environment and physical exercise participation (Henderson, Grode, O'Connell, \& Schwartz, 2015; Oyeyemi, Adewale, Sandra et al., 2016).

In developed countries, physical exercises of moderate intensity have been widely used as a method to prevent NCDs, and enhancing health and quality of life since 1996, with the release of the first report by the US Surgeon General on the benefits of physical activity and health (Jennifer M. Johnson, 1996). However, little attention has been devoted to physical exercise in the healthcare system of developing countries, including Ethiopia, with the barriers to its exclusion being unclear.

The rationale of focusing on physical exercise is that Ethiopians cannot afford the medical cost associated with medicated treatments, and if used, physical exercise programs are one of the most widely used costs effective way not only to prevent but also to reduce the risk for major NCDs. The aim of this study was, therefore, to determine the barriers preventing the integration of physical exercise in the Ethiopian healthcare system to treat NCDs. Their identification will provide healthcare organizations and policymakers with evidence to re-design their existing healthcare strategies and policies, specifically to address the growing burden of NCDs.

\section{Materials and Methods}

\subsection{Study Design}

A mixed research method sequential explanatory design was used in this study. A mixed methods research design is a procedure for collecting, analyzing and "mixing" both quantitative and qualitative methods in a single study or a series of studies to understand a research problem (Creswell \& Clark, 2007). According to Devers \& Frankel, (2014), the sequential explanatory design collects quantitative and qualitative information sequentially in two phases with one form of data collection following and informing the other. An explanatory sequential mixed methods design (a two-phase model) consists of first collecting quantitative data and then collecting qualitative data to help explain on the quantitative results (Guetterman \& Creswell, 2015). The rationale for this design is that its methodological pluralism that frequently results in research, which provides broader perspectives than those offered by mono method designs. The overall purpose and central premise of mixed methods is that the use of quantitative and qualitative approaches in combination provides a better understanding of research problems and complex phenomena than either approach alone (Creswell \& Clark, 2007; Guetterman \& Creswell, 2015).

\subsection{Setting}

The study was conducted in Ethiopia, at 13 public referral hospitals namely: Adama, Assossa, Black Lion, Dagimawi Minlik, Debre Berhan, Bishoftu, Felege Hiywot, Hawassa Adare, Jima University, Nekemitee, Pawie, Shashamane, and the University of Gondar hospitals due to their providing tertiary healthcare, particularly on NCDs.

\subsection{Participants}

The study was conducted in two phases due to the explanatory sequential design, with 99 purposively selected physicians. Purposive sampling is used when the researcher need the opinions and assessment of people with a high degree of knowledge and information about the study unit or organization (Gentles, Charles, Ploeg, \& Mckibbon, 2015; Palinkas et al., 2015b). Therefore, the researchers used purposive sampling because the 99 physicians were the only specialists working on NCDs treatment and prevention with a high degree of knowledge in the sampled regions and selected hospitals. Additionally, it is indicated that purposive sampling is more appropriate when the population number is small (Kothari, 2004; Creswell \& Clark, 2007). The 213 nurses being proportionately and randomly selected from their respective hospital for Phase I (quantitative) of the study. For Phase II (qualitative), six national health bureau officers were purposively selected. Participants with at least three years' work experience in a hospital treating NCDs related conditions were considered for inclusion.

\subsection{Data Collection}

Data collection was completed in two phases, the first being a quantitative questionnaire with healthcare professionals, and the second consisting of interviews with hospital national healthcare bureau officers. For Phase I, a self-administered questionnaire was developed after intensive literature study and validated by conducting a pilot test. As such a questionnaire did not exist, the researcher developed a questionnaire for the purposes of this study and it was piloted on two other hospitals not included in this study on 30 practitioners (physicians and nurses) to ensure it is valid and reliable. It was checked by a biostatistician before commencing data collection, the significance threshold being set at $p<0.05$ and a Cronbach's Alpha 0.814 being obtained. To ensure smooth 
administration of the structured questionnaire, participants were orientated and informed regarding the objectives of the study, relevance of the study, confidentiality of information, respondent's rights, informed consent and techniques of responding. The entire data collection process was also supervised by the researcher to ensure that the information was recorded correctly.

Healthcare professionals who consented to participate in the study and met the inclusion criteria completed the questionnaire which consisted of two sections: 1) the participants' demographic characteristics, and 2) barriers to integrating physical exercise into the healthcare system, and health information coverage of physical exercise benefits to treat NCDs. For section 1, the gender, age, marital status, service year, and specialization of the respondents were captured. For section 2, participants were requested to rate their answers on a 5-point Likert scale ranging from "Strongly Disagree" (1) to "Strongly Agree" (5) for physical exercise barriers, and from "Poor" (1) to "Excellent" (5) for health information coverage of physical exercise participation. A trained fieldworker administered the questionnaires after each participant had been informed about the aim of the study and provided their informed consent.

In Phase II, interviews were conducted with 13 hospital managers and six national health bureau officers to obtain their personal opinion on the existing barriers that prevent the integration of physical exercise to treat NCDs, and health information coverage of physical exercise benefits in Ethiopia.

\subsection{Statistical Analysis}

The Statistical Package for Social Science (SPSS) version 24 was used to analyse the quantitative data. Descriptive statistical analysis was done to indicate the socio-demographic characteristics of participants. The statistical measures such as mean and one sample t-test were used to identify whether the mean score was significantly different from a scalar value to measure the barriers to physical exercise. A Binomial test was applied to test whether a significant proportion of respondents rated health information coverage of physical exercise participation as 'poor'. All tests were conducted to show $95 \%$ confidence intervals and to recognize a $5 \%$ level of significance. All means were considered significantly different at $p<0.05$. The qualitative information obtained via the interview was transcribed and transferred into the Nvivo11 software program. The interviews were audio taped, to substantiate field notes taken by the investigator. The data collected through the interview was transcribed verbatim in to text files, described for and explained, to be meaningful in terms of the partakers' description of the condition stating themes and consistencies. In a mixed research method sequential explanatory design, the integration of the quantitative and qualitative results is done by writing and presenting the data in a discussion jointly (Guetterman \& Creswell, 2015). Similarly, the separate quantitative and qualitative results in this study were mixed in the discussion part of each manuscript.

\subsection{Ethical Consideration}

Ethical clearance was obtained from the Ethical review committee at the University of KwaZulu-Natal (reference number HSS/0683/015D), and permission to conduct the study in Ethiopia was obtained from the Ethiopian Ministry of Health. To obtain informed consent, the participants were given an information sheet, then signed an informed consent for being part of the study as well as agreed to be recorded. As the participants may need full information about the research including the reasons they have been chosen to participate the researcher explained precisely and clearly all important points to them. Participants' privacy, confidentiality and anonymity were guaranteed. Participants were given the opportunity to ask questions. The participants who showed their interest to continue, received informed consent forms and preparations that will enable them to participate in the study was discussed. Informed consent was completed at two stages in the study, firstly prior to the quantitative phase and again prior to the qualitative phase.

\section{Results}

\subsection{Phase I-Quantitative Results}

The 312 participant's socio-demographic (Table 1) showed that the majority were males 195 (62.5\%), most were between 27-33 years of age $(n=181,58.0 \%)$, and were married $(n=255,81.7 \%)$. Of the 212 nurses who participated, $209(67.0 \%)$ were general nurses. Of the 99 physicians, most were general practitioners $(\mathrm{n}=72$, $23.1 \%)$. Over half of the respondents had 3-8 service years ( $\mathrm{n}=179,57.4 \%)$, with very few $13(4.2 \%)$ having $15-20$ service years. 
Table 1. Socio-demographic characteristics of the respondents $(\mathrm{N}=312)$

\begin{tabular}{|c|c|c|c|c|c|}
\hline Characteristics & $\mathbf{N}$ & $\%$ & Characteristics & $\mathbf{n}$ & $\%$ \\
\hline Gender & & & Specialization & & \\
\hline Male & 195 & 62.5 & Specialist physician & 17 & 5.4 \\
\hline Female & 117 & 37.5 & General practitioners & 72 & 23.2 \\
\hline Age group & & & Health team manager & 12 & 3.8 \\
\hline $20-26$ & 5 & 1.6 & General nurse & 209 & 67.0 \\
\hline $27-33$ & 181 & 58.0 & Clinical nurse & 2 & 0.6 \\
\hline $34-40$ & 107 & 34.3 & Years' service & & \\
\hline $41-46$ & 19 & 6.1 & $3-8$ & 179 & 57.4 \\
\hline Marital status & & & $9-14$ & 120 & 38.5 \\
\hline Single & 57 & 18.3 & $15-20$ & 13 & 4.1 \\
\hline Married & 255 & 81.7 & & & \\
\hline
\end{tabular}

\section{Barriers to integrate physical exercise into the healthcare system}

Barriers to integrating physical exercise into the healthcare system are presented in Figure 1 and Table 2. There was significant agreement about the barriers to integrating physical exercise into the Ethiopian healthcare system. These were a lack of: national coordination to promote physical exercise $(100 \%, \mathrm{t}(311)=69.20, p<.0005)$, trained physical exercise professionals $(83 \%, \mathrm{t}(311)=14.42, p<.0005)$, physical exercise guidelines $(90.7 \%, \mathrm{t}$ $(311)=33.25, p<.0005)$; education about physical exercise by healthcare providers $(99 \%, \mathrm{t}(311)=62.94, p$ $<.0005)$; information on the health benefits of physical exercise to give their patients $(100 \%, \mathrm{t}(311)=65.62, p$ $<.0005)$; and a suitable built environment that encourages physical exercise participation $(99 \%, \mathrm{t}(311)=59.64, p$ $<.0005)$.

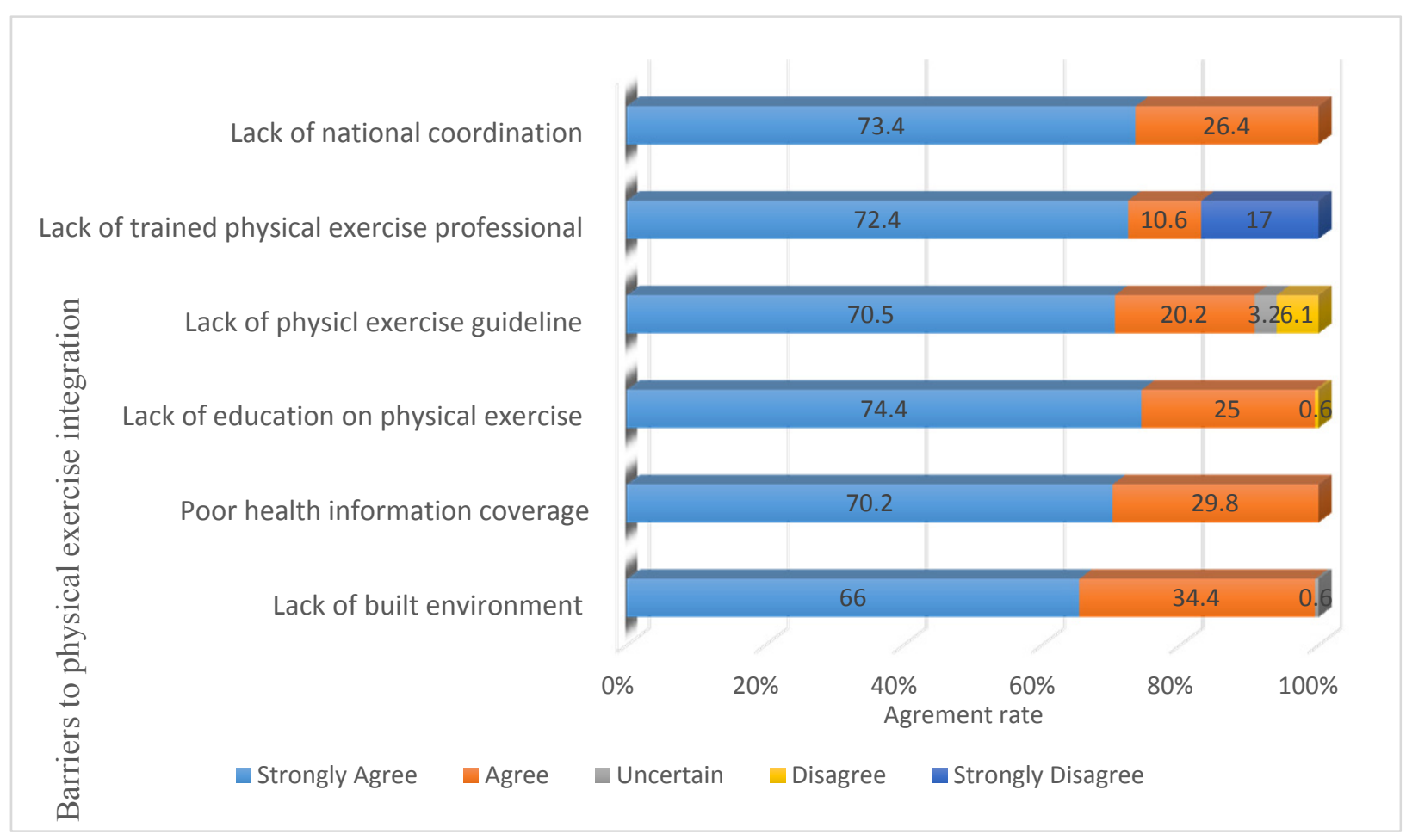

Figure 1. Percentage rating of barriers to physical exercise integration

The mean rating of barriers to integrating physical exercise into the healthcare system are presented in table 2 . As 
showed in the table, a lack of national coordination to promote physical exercise $(\mathrm{M}=4.7, \mathrm{SD}=.443), \mathrm{t}(311)=$ $69.20, p<.0005)$, education about physical exercise by healthcare providers $(\mathrm{M}=4.73, \mathrm{SD}=.486), \mathrm{t}(311)=62.94$, $p<.0005)$; information on the health benefits of physical exercise to give their patients $(\mathrm{M}=4.70, \mathrm{SD}=.458), \mathrm{t}$ $(311)=65.62, p<.0005)$; and a suitable built environment that encourages physical exercise participation $(\mathrm{M}=$ $4.65, \mathrm{SD}=.490), \mathrm{t}(311)=59.64, p<.0005)$ were the top four barriers to integrate physical exercise into the Ethiopian healthcare system.

Table 2. Barriers to integrate physical exercise into the healthcare system

\begin{tabular}{lllllllll}
\hline \multirow{2}{*}{ Lack of: } & \multicolumn{9}{l}{$\mathbf{9 5 \%} \mathbf{C I}$} & \multicolumn{1}{l}{$\mathbf{l}$} & & & & & \\
\cline { 2 - 9 } & Mean & SD & T & df & $\boldsymbol{p}$-value & Mean Df & Lower & Upper \\
\hline 1. National coordination & 4.73 & .443 & 69.202 & 311 & .000 & 1.734 & 1.68 & 1.78 \\
2. Trained professional & 4.21 & 1.488 & 14.420 & 311 & .000 & 1.215 & 1.05 & 1.38 \\
3. Practical guide & 4.55 & .824 & 33.252 & 311 & .000 & 1.551 & 1.46 & 1.64 \\
4. Education & 4.73 & .486 & 62.935 & 311 & .000 & 1.731 & 1.68 & 1.78 \\
5. Information & 4.70 & .458 & 65.616 & 311 & .000 & 1.702 & 1.65 & 1.75 \\
6. Built environment & 4.65 & .490 & 59.640 & 311 & .000 & 1.654 & 1.60 & 1.71 \\
\hline
\end{tabular}

\section{Health information coverage of the importance of physical exercise participation}

Regarding the coverage of physical exercise as part of health information (Table 3), in each case, a significant proportion rated the coverage as poor. All healthcare workers (100\%) rated media coverage (radio and television), newspaper, the internet, and mobile SMS coverage on the benefits of physical exercise as 'poor' $(p<.0005)$. The majority $(89 \%)$ also rated the coverage on the benefits of physical exercise given by health professionals during health education as 'poor' $(p<.0005)$, with the rest indicating that it was fair. Similarly, three-quarters $(76 \%)$ rated health professional's communication about the benefits of physical exercise with their patients as 'poor' ( $p$ $<.0005$ ), with the remainder considering it to be 'fair'.

Table 3. Health information coverage on the benefits of physical exercise

\begin{tabular}{lllllll}
\hline & Items & Category & $\mathbf{n}(\%)$ & Observed Prop. & Test Prop. & $\boldsymbol{p}$-value \\
\hline 1. & Media coverage & Poor & $312(100)$ & 1.00 & .50 & $.000^{\mathrm{a}}$ \\
2. & Newspaper coverage & Poor & $312(100)$ & 1.00 & .50 & $.000^{\mathrm{a}}$ \\
3. & Internet coverage & Poor & $312(100)$ & 1.00 & .50 & $.000^{\mathrm{a}}$ \\
4. & Mobile SMS coverage & Poor & $312(100)$ & 1.00 & .50 & $.000^{\mathrm{a}}$ \\
& & Poor & $277(89)$ & .89 & & \\
5. Health professionals' coverage & Fair & $35(11)$ & .11 & .50 & $.000^{\mathrm{a}}$ \\
& & Total & $312(100)$ & 1.00 & & \\
& & Poor & $236(76)$ & .76 & & $.000^{\mathrm{a}}$ \\
6. Health professional's communication & Fair & $76(24)$ & .24 & .50 & \\
\hline
\end{tabular}

Based on Z Approximation

\subsection{Phase 2 - Qualitative Results}

The following questions were used in the interviews with the hospital managers to obtain their opinions concerning the barriers to integrating physical exercise into the healthcare system.

\section{Q1. What are the barriers to integrating physical exercise in your hospital's healthcare system?}

The participants indicated four additional barriers, with the poorly designed Ethiopian healthcare policy: “...the 
barriers may be related to building environment, the lifestyle of healthcare professionals, health information coverage of physical exercise, health policy, and the physical building of the hospitals."

\section{Q2. What built environmental aspects prevent physical exercise integration in your hospital?}

The participants reflected that the existing hospitals are built without taking into account non-pharmacological practices of healthcare.

“.... many hospitals in our country are old buildings and the design, the physical environment and the entire environment of the hospitals are inconvenient for using physical exercise to treat NCDs. The hospitals are facing a resource constraint, such as lack of physical assessment, physical exercise prescription, referral and practice centres."

\section{Q3. How do you rate health information coverage of physical exercise benefits?}

Interviews depicted poor health information coverage as a barrier to physical exercise integration and participation: “...mass media coverage of physical exercise benefits, like radio, television (TV), newspaper, and mobile short message service (SMS) is inadequate. I think the awareness created by healthcare providers to the patients on the health benefits of physical exercise is insufficient."

\section{Q4. What are the barrier related to healthcare professionals to physical exercise integration into their} work?

The interviews indicated that the lifestyle of healthcare providers is the other barrier to integrating physical exercise into their work: “...most healthcare providers may not have active lifestyles may be due to lack of time for physical exercise, skill of physical exercise, confidence, knowledge of physical exercise, and prioritizing clinical matters which may enable them not to use physical exercise in the healthcare system."

The interviews also indicted that demographic factors of healthcare professionals as a barrier to integrate physical exercise in the healthcare system to treat NCDs patients. "...in my opinion, being female, old age, having mirage, specialization of healthcare providers and service year may affect the integration of physical exercise in the healthcare system."

In addition the respondents reflect that experience of healthcare professionals associated with physical exercise integration in healthcare stating "...experience can be a barrier to integrate physical exercise in the healthcare to treat NCDs. Forex instance, lack of practical experience on the type, duration, intensity, and frequency of exercise to be integrated in healthcare to treat NCDs are barriers among healthcare professionals."

\section{Q5. What are the health policy-related barriers to integrating physical exercise to treat NCDs?}

The respondents reflected that the lack of a national strategy and policy on physical exercise were barriers to integrating physical exercise into the healthcare system: “... I think national coordination and strategic policy that integrates and promote physical exercise participation is lacking. The reason can be that higher level leaders do not have a good attitude to physical exercise." "...the lack of physical exercise in the medical education curriculum can be pocked as barriers."

The limited policy on NCDs prevention was also described as barriers to integrating physical exercise into the healthcare system: “...the health policy remain discriminatory, the focus is on drug prescription to cure diseases. Prevention of NCDs through physical exercise prescription is disregarded in the national health policy. It requires further attention."

\section{Q6. What are hospital related barriers to physical exercise integration to treat NCDs?}

Insufficient infrastructure and lack of professionals in the hospitals were stated by the respondents as a barrier: "...there is no gymnasium, active physical assessment centre, and trained professional in physiotherapy and physical exercise expert for exercise referral."

The respondents indicated the lack of physical exercise guidelines in the hospitals prevents the use of physical exercise to treat NCDs: "...physical exercise guidelines that help healthcare provider the type, intensity, duration, and frequency of physical exercise to be prescribed to patients is lacking in hospitals."

\section{Discussion}

As this study aimed to explore the barriers preventing healthcare workers to integrate physical exercise into Ethiopian hospitals, with six being identified in Phase I (qualitative questionnaires) and four in Phase II (interviews). The six barriers identified through the questionnaires with the 312 participants indicated a lack of: national coordination to promote physical exercise, trained physical exercise professionals, physical exercise 
guidelines, education about physical exercise by healthcare providers, information on the health benefits of physical exercise to give their patients, and built environment that encourages physical exercise participation.

The lack of national coordination was found the first barrier preventing healthcare professionals' use of physical exercise in the healthcare system. In contrast with our study, countries such as South Africa, Kenya, and Ghana integrated the Exercises is Medicine (EIM) initiative into their national healthcare system and use it as one method of clinical practice (ACSM, 2017). These countries are working at national level to create awareness in training, and accrediting healthcare providers and physical exercise professionals, together with EIM related public health promotion (Annan, 2013; Holtzhausen, 2013). The apparent lack of national coordination to promote physical exercise in Ethiopia can be attributed to the absence of physical exercise strategy in the national health policy, and the lack of a functioning national NCDs prevention strategy. Similarly, the lack of national coordination could be interpreted as the result of a lack of a joint and cooperative effort to promote physical exercise among healthcare organizations and policy makers in Ethiopia in collaboration with local (media and telecommunication) and international organizations, as is the case in other countries.

Secondly, the lack of professional physical exercise experts in hospitals are demonstrated as barriers to integrating physical exercise for NCDs prevention. Unlike our study, Dunlop \& Murray, (2013) and Thornton et al., (2016) reported the availability of physical exercise professionals' in the healthcare to treat NCDs patients using physical exercise. This difference could be attributed to the variation in the national health policy and medical education curriculum.

Our study indicated the third barrier to be the lack of practical guidelines on how to prescribe physical exercise as a barrier to use physical exercise in healthcare. Previous research demonstrated that healthcare professionals who use physical exercise guidelines, use physical exercise to treat NCDs patients more confidently than who are not using it (Brien et al., 2017). The lack of physical exercise guidelines in Ethiopian healthcare system possibly justifies the lack of understanding about the health benefits of physical exercise among policymakers and absence of physical exercise as a strategy for NCDs prevention in the national health policy.

The lack of information on the benefits of physical exercise and lack of education about physical exercise among healthcare providers were cited as a barrier to use physical exercise for clinical practice. In accordance with our study, Soundy et al. (2014); Brien, Shields, Oh, and Fowles (2017) showed that healthcare practitioners who lack information and education about physical exercise are less likely to use it in their NCDs patients' treatment. The possible reason for the lack of information and education of physical exercise could be attributed to the lack of short- and long-term training among healthcare providers on how to prescribe physical exercise to patients. It is evidenced that nurses and physicians who had short-term training on physical exercise are more likely to apply physical exercise in clinical practice than those who did not train (Brien et al., 2017).

The built environment was the sixth barrier that prevents health care professionals' the use of physical exercise to prevent NCDs. Consistent with our study, other research indicates an association between the built environment and physical exercise prescription by healthcare providers (Sallis et al., 2016; Crochemore et al., 2017). The possible reason could be attributed to the lack of infrastructures, such as physical exercise centres, gymnasiums, and assessment and referral schemes in the Ethiopian hospitals.

The qualitative study identified five barriers such as the built environment, health policy, healthcare professionals' lifestyle, health information coverage of physical exercise and the hospital physical building as barriers to integrating physical exercise into the healthcare system. Our study corroborates the findings of other researchers who indicated that lack of time, skill, confidence and prioritizing clinical matters as a barrier to physical exercise integration (Matthews \& Kirk, 2014; Brien et al., 2017). Similarly, Dunlop and Murray (2013) indicated that most United Kingdom medical students do not have the relevant knowledge and skills to promote physical exercise among their patients. In line with our study, Galaviz, Fabrigar, and Taylor, (2015) showed the barriers associated with physicians to be a lack of knowledge about exercise prescription, and a lack of skill on how to use guidelines to integrate physical exercise into the healthcare system (Persson, Brorsson, Ekvall Hansson, Troein, \& Strandberg, 2013).

The results of our study showed the lifestyle of healthcare professionals as a barrier to using physical exercise for clinical practice, which is supported by the findings of Lyle, (2013). Busy work time due to clinical matters, lack of physical exercise skill, and do not seeing the need for it could be the reasons for healthcare professionals' lack of physical exercise. The evidence demonstrated that healthcare providers who are not participating in regular physical exercise programs are less likely to counsel and prescribe physical exercise to patients during clinical practice (Morishita et al., 2014). 
Our study revealed health policy-related barriers, such as the lack of a physical exercise policy, national coordination to promote physical exercise, practical guidelines for exercise prescription and physical exercise as a course in the medical curriculum. The finding of our research on the lack of practical guidelines for exercise prescription is contrasting a study by Stoutenberg, Stasi, Stamatakis, Danek, \& Trilk, (2015), which reported the presence of guidelines and physical exercise in all medical schools of the USA. The finding of our study demonstrated that lack of physical exercise guidelines and lack of professional physical exercise experts in hospitals are hospital-related barriers to integrate physical exercise for NCDs prevention. Unlike our study Dunlop \& Murray, (2013) and Thornton et al., (2016) reported the availability of physical exercise guidelines and physical exercise professionals' in the hospitals to treat NCDs. This difference could be attributed to the variation in the national health policy and medical education curriculum.

Our study revealed information related barriers, such as poor social media coverage, mobile SMS, the internet and poor coverage by health professionals on the benefits of physical exercise during health education in medical wards. Contrary to our study, other researchers showed the effective use of the internet (Huberty, Dinkel, Beets, \& Coleman, 2013; Duncan et al., 2014), social media (Laranjo, Mortimer, Mendes, \& Lau, 2015), mobile SMS (Muntaner \& Vidal-conti, 2016), and health professionals counselling of physical exercise (Lobelo, Steinacker, Duperly, \& Hutber, 2014) as possible ways of exercise promotion in the healthcare system. The poor health information coverage of physical exercise in Ethiopia is possibly due to lack of national coordination to promote physical activity in the population in collaboration with multiple media and health information roots.

\section{Conclusion}

To our knowledge, this study is the first that attempts to explore the barriers healthcare providers face integrating physical exercise into the healthcare system to prevent NCDs in Ethiopia. The results revealed a number of barriers, including those associated with the built environment, health policy, healthcare professionals' lifestyle, and health information coverage of physical exercise, and national coordination to promote physical exercise. We speculate that unless the barriers to integrating physical exercise are addressed, physical exercise remains marginalized from the Ethiopian healthcare system. The cited barriers are indicators that can be used by healthcare organizations and policymakers to plan, design and integrate physical exercise strategies effectively into the healthcare setting and to redesign the existing health policy. In addition, training of healthcare workers on physical exercise prescription at all levels of medical education is required. Multi-sectoral collaboration is also required to remove the barriers and integrate physical exercise into the healthcare system for clinical practice. Finally, further studies are required to explore healthcare providers' physical exercise prescription practices, and more effort should be made to develop, coordinate and initiate a physical exercise referral scheme.

\section{Authors' Contribution}

The authors contributed equally.

\section{Acknowledgements}

The authors acknowledge all the participants in this study for their commitment by providing the required information to make this study complete.

\section{Competing Interests Statement}

The authors declare that there is no competing associated with the publication of this manuscript.

\section{References}

Annan, A. E. (2013). Exercise is medicine practice in Ghana. EIM Ghana, 6(June), 1-57.

Archer, E., \& Blair, S. N. (2012). Physical Activity, Exercise and Non-Communicable Diseases. Res Exerc Epidemiol, 14(1), 1-18.

Bishwajit, G., Ide, S., Hossain, M. A., \& Safa, N. (2014). Trade Liberalization , Urbanization and Nutrition Transition in Asian Countries. Journal of Nutritional Health \& Food Science Open, 2(1), 1-5. https://doi.org/10.15226/jnhfs.2014.00109

Brien, M. W. O., Shields, C. A., Oh, P. I., \& Fowles, J. R. (2017). Health care provider confidence and exercise prescription practices of Exercise is Medicine Canada workshop attendees. NRC Research Press, 42(14 December), 384-390.

Brookfield, K., \& Mead, G. (2016). Physical environments and community reintegration post stroke: qualitative insights from stroke clubs. Disability \& Society, 31(8), 1013-1029. https://doi.org/10.1080/09687599.2016.1223606. 
Creswell, J. W., \& Clark, V. L. P. (2007). Designing and conducting mixed methods research. Australian and New Zealand Journal of Public Health, 31(4), 273.

Crochemore, I., Hino, A. A., Lopes, A., Ekelund, U., Brage, S., Gonçalves, H., ... Hallal, P. C. (2017). Built environment and physical activity: domain- and activity-specific associations among Brazilian adolescents. MBC Public Health, 17(616), 1-11. https://doi.org/10.1186/s12889-017-4538-7.

Devers, K. J., \& Frankel, R. M. (2014). Study Design in Qualitative Research-2: Sampling and Data Collection Strategies.

Duncan, M., Vandelanotte, C., Kolt, G. S., Rosenkranz, R. R., Caperchione, C. M., George, E. S., ... Mummery, W. K. (2014). Effectiveness of a web- and mobile phone-based intervention to promote physical activity and healthy eating in middle-Aged males: Randomized controlled trial of the manup study. Journal of Medical Internet Research, 16(6), 1-21. https://doi.org/10.2196/jmir.3107

Dunlop, M., \& Murray, A. D. (2013). Major limitations in knowledge of physical activity guidelines among UK medical students revealed: implications for the undergraduate medical curriculum: Table 1. British Journal of Sports Medicine, 47(11), 718-720. https://doi.org/10.1136/bjsports-2012-091891

Duperly, J., Collazos, V., Paez, C., Donado, C., Pratt, M., \& Lobelo, F. (2014). Exercise is Medicine in Latin America : training health care professionals in physical activity prescription. Schweizerische Zeitschrift Für Sportmedizin Und Sporttraumatologie, 62(2), 38-41.

Eckert, Sophie, S. K. (2014). Urbanization and Health in Developing Countries: A Systematic Review. World HealtH \& PoPulation, 15(1), 7-20. https://doi.org/10.12927/whp.2014.23722

Engelen, L., Bauman, A., Bellew, B., Caillaud, C., Merom, D., Singh, M. F., ... Network, A. (2017). Capacity building in physical activity and non-communicable disease prevention: a low-cost online training course can reach isolated practitioners. Global Health Promotion, 24(1), 27-33. https://doi.org/10.1177/1757975915586957.

Fatt, Q. K. (2016). Non-Communicable Diseases: A Major Problem Worldwide. Public Health - Open JournalOpen Journal, 1(2), 32-35. https://doi.org/10.17140/PHOJ-1-107.

Firth, J., Rosenbaum, S., Stubbs, B., Gorczynski, P., Yung, A. R., \& Vancampfort, D. (2016). Motivating factors and barriers towards exercise in severe mental illness: a systematic review and meta- analysis. Psychological Medicine (2016), 46(9), 2869-2881. https://doi.org/10.1017/S0033291716001732

Galaviz, K. I., Jauregui-Ulloa, E., Fabrigar, L. R., Latimer-Cheung, A., Lopez Y Taylor, J., \& Lévesque, L. (2015). Physical activity prescription among Mexican physicians: A structural equation analysis of the theory of planned behaviour. International Journal of Clinical Practice, 69(3), 375-383. https://doi.org/10.1111/ijcp.12546

Guetterman, T. C., \& Creswell, J. W. (2015). Integrating Quantitative and Qualitative Results in Health Science Mixed Methods Research Through Joint Displays. Ann Fam Med, 13(6), 554-561. https://doi.org/10.1370/afm.1865

Hallal, P. C., Andersen, L. B., Bull, F. C., Guthold, R., Haskell, W., Ekelund, U., ... Group, W. (2012). Physical Activity 1 Global physical activity levels: surveillance progress , pitfalls. The Lancet, 380(9838), 247-257. https://doi.org/10.1016/S0140-6736(12)60646-1

Henderson, K. E., Grode, G. M., O'Connell, M. L., \& Schwartz, M. B. (2015). Environmental factors associated with physical activity in childcare centers. International Journal of Behavioral Nutrition and Physical Activity, 12(1), 43. https://doi.org/10.1186/s12966-015-0198-0

Hinckson, E. A., Duncan, S., Oliver, M., Mavoa, S., Cerin, E., Badland, H., ... Schofield, G. (2014). Built environment and physical activity in New Zealand adolescents: a protocol for a cross-sectional study: Table 1. BMJ Open, 4(4), e004475. https://doi.org/10.1136/bmjopen-2013-004475

Hoeger, W., \& Hoeger, S. (2015). Life time Physical Fitness and Wellness: A personalized Program (13 th ed., pp. 1-539). USA: Cengage Learning. https://doi.org/10.1136/bjsm.2010.083469

Holtzhausen, L. (2013). Exercise Is Medicine South Africa. Division Sport and Exercise Medicine School of Medicine, 27(0), 1-38.

Huberty, J., Dinkel, D., Beets, M. W., \& Coleman, J. (2013). Describing the use of the internet for health, physical activity, and nutrition information in pregnant women. Maternal and Child Health Journal, 17(8), 1363-1372. 
https://doi.org/10.1007/s10995-012-1160-2

Jennifer M. Johnson, S. D. B. (1996). Surgeon General's Report on Physical Activity and Health. JAMA, 276(7), 522. https://doi.org/doi:10.1001/jama.1996.03540070018010

Kay, S., \& Nagesha, V. (2016). The Demographic Profile of African Countries. Addis Ababa, Ethiopia: Economic Commission for Africa.

Kohl, H. W., Craig, C. L., Lambert, E. V., Inoue, S., Alkandari, J. R., Leetongin, G., ... Wells, J. C. (2012). The pandemic of physical inactivity: Global action for public health. The Lancet, 380(9838), 294-305. https://doi.org/10.1016/S0140-6736(12)60898-8.

Kokkinos, P. (2012). Physical Activity, Health Benefits, and Mortality Risk. ISRN Cardiology, 2012(October 2012), 1-14. https://doi.org/10.5402/2012/718789

Kothari, C. R. (2004). Research Methodology (2nd ed.). 4835/24, Ansari Road, Daryaganj, New Delhi - 110002: New Age International (P) Ltd., Publishers.

Krueger, H., Turner, D., Krueger, J., \& Ready, A. E. (2014). The economic benefits of risk factor reduction in Canada: tobacco smoking, excess weight and physical inactivity. Canadian Journal of Public Health = Revue Canadienne de Santé Publique, 105(1), e69-e78. Retrieved from http://www.embase.com/search/results?subaction=viewrecord\&from=export\&id=L601526305\%5Cnhttp://r esolver.lib.washington.edu/resserv?sid=EMBASE\&issn=19207476\&id=doi:\&atitle=The+economic + benefit $\mathrm{s}+$ of + risk + factor+reduction + in + Canada $\% 3 \mathrm{~A}+$ tobacco + smoking $\% 2 \mathrm{C}+$ excess

Laranjo, L., Mortimer, N., Mendes, G. A., \& Lau, A. Y. S. (2015). The influence of social networking sites on health behavior change : a systematic review and meta-analysis. J Am Med Inform Assoc, 22(8 July 2014), 243-256. https://doi.org/10.1136/amiajnl-2014-002841.

Lee, I.-M., Shiroma, E. J., Lobelo, F., Puska, P., Blair, S. N., \& Katzmarzyk, P. T. (2012). Impact of Physical Inactivity on the World's Major Non-Communicable Diseases. The Lancet, 380(9838), 219-229. https://doi.org/10.1016/S0140-6736(12)61031-9

Lobelo, F., Steinacker, J., Duperly, J., \& Hutber, A. (2014). Physical Activity Promotion in Health Care Settings: the "Exercise is Medicine" Global Health Initiative Perspective. Schweizerische Zeitschrift Für Sportmedizin \& Sporttraumatologie, 62(2), 42-45. Retrieved from http://search.ebscohost.com/login.aspx?direct=true\&db=sph\&AN=96712581\&site=ehost-live

Lobelo, F., Stoutenberg, M., \& Hutber, A. (2014). The Exercise is Medicine Global Health Initiative: A 2014 update. British Journal of Sports Medicine, 48(22), 1627-1633. https://doi.org/10.1136/bjsports-2013-093080

Lyle, R. M. (2013). Barriers in the Implementation of a Physical Activity Intervention in Primary Care Settings: Lessons Learned. Health Promotion Practice, 14(1), 81-87. https://doi.org/10.1177/1524839910392991

Matthews, L., \& Kirk, A. (2014). Insight from health professionals on physical activity promotion within routine diabetes care. Physical Activity for Health Research Group, 31(3), 111-116. https://doi.org/10.1002/pdi.1844

Mensah, G. A. (2016). Tackling Noncommunicable Diseases in Africa. Health Education \& Behavior, 43(1s), 7S-13S. https://doi.org/10.1177/1090198116633454

Morishita, Y., Numata, A., Miki, A., Okada, M., Ishibashi, K., Takemoto, F., .. Kusano, E. (2014). Primary care physicians ' own exercise habits influence exercise counseling for patients with chronic kidney disease: a cross-sectional study. BMC Nephrology, 15(48), 1-7. https://doi.org/10.1186/1471-2369-15-48

Muntaner, A., \& Vidal-conti, J. (2016). Increasing physical activity through mobile device interventions: A systematic review. Health Informatics Journal, 22(3), 451-469. https://doi.org/10.1177/1460458214567004

Ng, S. W., \& Popkin, B. M. (2012). Time use and physical activity: A shift away from movement across the globe. Obesity Reviews, 13(8), 659-680. https://doi.org/10.1111/j.1467-789X.2011.00982.x

Nunan, D., Mahtani, K. R., Roberts, N., \& Heneghan, C. (2013). Physical activity for the prevention and treatment of major chronic disease: an overview of systematic reviews. Systematic Reviews, 2(1), 56. https://doi.org/10.1186/2046-4053-2-56

Oyeyemi, A. L., Kasoma, S. S., Onywera, V. O., Assah, F., Adedoyin, R. A., Conway, T. L., ... Sallis, J. F. (2016). NEWS for Africa: adaptation and reliability of a built environment questionnaire for physical activity in seven African countries. International Journal of Behavioral Nutrition and Physical Activity, 13(1), 33. 
https://doi.org/10.1186/s12966-016-0357-y

Pearce, N., Ebrahim, S., Mckee, M., Lamptey, P., Barreto, M. L., Matheson, D., .. Vineis, P. (2013). The road to $25 \times 25$ : how can the five-target strategy reach its goal? The Lancet Global Health, 2(3), e126-e128. https://doi.org/10.1016/S2214-109X(14)70015-4.

Persson, G., Brorsson, A., Ekvall Hansson, E., Troein, M., \& Strandberg, E. L. (2013). Physical activity on prescription (PAP) from the general practitioner's perspective - A qualitative study. BMC Family Practice, 14(128), 1-8. https://doi.org/10.1186/1471-2296-14-128

Reis, R. S., Salvo, D., Ogilvie, D., Lambert, E. V., Goenka, S., \& Brownson, R. C. (2016). Scaling up physical activity interventions worldwide: stepping up to larger and smarter approaches to get people moving. The Lancet, 388(10051), 1337-1348. https://doi.org/10.1016/S0140-6736(16)30728-0

Rikli, R. E. (2005). Movement and Mobility Influence on Successful Aging: Addressing the Issue of Low Physical Activity. National Association for Kinesiology and Physical Education in Higher Education, 57, 46-66. https://doi.org/10.1080/00336297.2005.10491842

Sallis, J. F., Cerin, E., Conway, T. L., Adams, M. A., Frank, L. D., Pratt, M., .. Owen, N. (2016). Physical activity in relation to urban environments in 14 cities worldwide: a cross-sectional study. Lancet, 387(15), $2207-2217$. https://doi.org/10.1016/S0140-6736(15)01284-2

Sallis, R. (2017). Exercise is medicine: a call to action for physicians to assess and prescribe exercise exercise. The Physician and Sportsmedicine, 43(1), 22-26. https://doi.org/10.1080/00913847.2015.1001938

Sallis, R., \& Permanente, K. (2017). Exercise Is Medicine. JACC: Cardiovascular Imaging, 85(N/A), 5651324. https://doi.org/10.3810/psm.1997.07.1495.

Shuval, K., Leonard, T., Drope, J., Katz, D. L., Patel, A. V., Maitin-Shepard, M., ... Grinstein, A. (2017). Physical activity counseling in primary care: Insights from public health and behavioral economics. $C A$ : $A$ Cancer Journal for Clinicians, 67(3), 233-244. https://doi.org/10.3322/caac.21394.

Soundy, A., Stubbs, B., Probst, M., Hemmings, L., \& Vancampfort, D. (2014). Barriers to and Facilitators of Physical Activity Among Persons With Schizophrenia: A Survey of Physical Therapists. Psychiatric Services, 65(5), 693-696. https://doi.org/10.1176/appi.ps.201300276

Speake, H., Copeland, R. J., Till, S. H., Breckon, J. D., Haake, S., \& Hart, O. (2016). Embedding Physical Activity in the Heart of the NHS: The Need for a Whole-System Approach. Sports Medicine, 46(7), 939-946. https://doi.org/10.1007/s40279-016-0488-y

Taylor, D. (2014). Physical activity is medicine for older adults. Postgraduate Medical Journal, 90(1059), $26-32$. https://doi.org/10.1136/postgradmedj-2012-131366

Thornton, J. S., Frémont, P., Khan, K., Poirier, P., Fowles, J., Wells, G. D., \& Frankovich, R. J. (2016a). Physical activity prescription: a critical opportunity to address a modifiable risk factor for the prevention and management of chronic disease: a position statement by the Canadian Academy of Sport and Exercise Medicine: Table 1. British Journal of Sports Medicine, 50(18), 1109-1114. https://doi.org/10.1136/bjsports-2016-096291

Thornton, J. S., Frémont, P., Khan, K., Poirier, P., Fowles, J., Wells, G. D., \& Frankovich, R. J. (2016b). Physical Activity Prescription. Clinical Journal of Sport Medicine, 26(4), $259-265$. https://doi.org/10.1097/JSM.0000000000000363

Varghese, C. (2013). WHO, Global action plan for the prevention and control of NCDs 2013-2. Retrieved from https://doi.org//entity/nmh/publications/ncd-action-plan/en/index.html.

Varghese, C. (2015). WHO Global Action Plan for the Prevention and Control of NCDs 2013-2020. Coordinator, NCD Management.

World Health Organizatio [WHO]. (2014). Global status report on alcohol and health (pp. 1-100). Retreived from https://doi.org//entity/substance_abuse/publications/global_alcohol_report/en/index.html

World Health Organizatio [WHO]. (2014). Global status report on noncommunicable diseases: "Attaining the nine global noncommunicable disease targets; a shared responsibility". World Health Organization. 1211 Geneva 27, Switzerland. https://doi.org/ISBN 9789241564854

World Health Organizatio [WHO]. (2017). Physical activity: Fact sheet. Retrieved from http://www.who.int/mediacentre/factsheets/fs385/en/. 
World Health Organizatio [WHO]. (2015). Noncommunicable Diseases Progress Monitor. https://doi.org/10.2766/120051

\section{Copyrights}

Copyright for this article is retained by the author(s), with first publication rights granted to the journal.

This is an open-access article distributed under the terms and conditions of the Creative Commons Attribution license (http://creativecommons.org/licenses/by/4.0/). 